\title{
Trabalhadores de rua: tensões e resistências na luta pelo direito ao trabalho
}

\author{
Aurineida Maria Cunha \\ Universidade Estadual do Ceará (UECE)
}

Trabalhadores de rua: tensões e resistências na luta pelo direito ao trabalho

Resumo: Este artigo tem como objetivo analisar os processos de redefinição dos espaços públicos tomando como referência a lógica de apropriação destes espaços pelos trabalhadores de rua de Fortaleza ${ }^{1}$ como contra-uso, sobretudo a partir das tensões que se erguem das diferentes possibilidades de uso e dos sentidos atribuídos pelos moradores, trabalhadores, comerciantes e frequentadores do Centro Histórico da cidade. Buscou-se contextualizar a intervenção da Prefeitura Municipal de Fortaleza e a luta política dos trabalhadores cadastrados e não-cadastrados para assegurarem seu trabalho e, consequentemente, sua sobrevivência. Os resultados da pesquisa indicaram que sobreviver na rua subverte as leis e os padrões formais do mercado na sociedade capitalista alicerçada no trabalho assalariado. Uma conclusão importante é que os trabalhadores de rua ao se apropriarem dos espaços públicos, alteram os usos esperados com um contra-uso que é estabelecido por disputas/tensões/resistências pelo direito ao trabalho.

Palavras-chave: trabalho, direito, espaços públicos.

\section{Street Workers: Tensions and Resistance in the Struggle for the Right to Work}

Abstract: The purpose of this article is to analyze the processes of redefinition of public spaces in relation to the logic of appropriation of these spaces by street workers in Fortaleza as a form of "counter-use". It focuses in particular on the tensions that arise from the different possibilities for use and the different meanings attributed to public spaces by residents, workers, shop owners and those who frequent the city's historic center. The paper sought to contextualize the intervention of the Fortaleza municipal government and the political struggle of formal and informal workers to assure their work, and as a consequence, their survival. The research results indicate that survival in the street subverts the laws and formal market standards of capitalist society, which is based on salaried work. An important conclusion is that by appropriating public spaces, the street workers alter the expected uses with a counter-use that is established by disputes and challenges to the right to work.

Key words: work, rights, public spaces. 


\section{Introdução}

Este artigo tem como objetivo analisar os processos de redefinição dos espaços públicos tomando como referência a lógica de apropriação desses espaços pelos trabalhadores de rua - em Fortaleza - como contra-uso na construção do direito ao trabalho. Buscamos suas explicações nas relações sociais estabelecidas nesses locais, nas mudanças dos padrões de produção e reprodução social, levando em conta a intervenção do Estado e a luta política dos trabalhadores. Utilizamos a lógica no sentido de que as coisas se constituem de contradições e forças antagônicas, movimentos e transformações constantes, e estão em contínua relação e inter-relação com outros fenômenos. Há uma distinção entre as coisas tal como aparecem e como são na realidade. Até porque toda a ciência seria supérflua se a forma de manifestação e a essência coincidissem imediatamente (MARX, 1987).

A cidade de Fortaleza foi escolhida como local da pesquisa devido às suas contradições e transformações nas duas últimas décadas. A capital do estado do Ceará passou por diferentes intervenções urbanísticas que contribuíram para alterar sua imagem histórica de cidade pobre, subdesenvolvida e dos retirantes das secas. Agora é vista como moderna, com infra-estrutura, lazer, cultura e belezas naturais, passível de ser vendida através de city marketing local, nacional e internacional, considerada modelo dos processos contemporâneos de renovação e reestruturação espacial no país. No discurso oficial, a modernização iria possibilitar a diminuição da pobreza e da miséria, porém a capital cearense continuou a apresentar uma profunda desigualdade social $^{2}$ e como uma das principais expressões da questão social, o trabalho precarizado, realizado pelos trabalhadores de rua nos espaços públicos da cidade.

Pesquisamos os trabalhadores de rua do Centro Histórico de Fortaleza, onde são desenvolvidas atividades comerciais, financeiras e de lazer, e onde se apresenta o maior número de espaços públicos. Foram entrevistados 20 trabalhadores cadastrados junto ao - Departamento de Comércio Ambulante de Fortaleza (DCA), que se apropriaram desses espaços, e na escolha, consideramos a visibilidade do trabalho (praças, ruas, calçadas) e o grau de conflito gerado pelo uso dos espaços públicos (poder público, lojistas). Para a análise, os trabalhadores de rua ${ }^{3}$ foram identificados por ordem alfabética (do entrevistado A ao entrevistado $\mathrm{U}$ ), pela idade e tempo de trabalho na rua.

\section{A heterogeneidade dos trabalhadores de rua e as tensões na apropriação dos espaços públicos}

Entendemos que o espaço público é locus de um determinado comportamento, de uma cultura públi- ca, e que deve assegurar as normas que garantam os direitos e deveres individuais relacionados com o conjunto da sociedade. "Não pode haver cidadania sem democracia, não pode haver cidadania sem espaços públicos, e o espaço público não pode existir sem dimensão física" (GOMES, 2002, p. 168). O espaço público também é um lugar de contradições, de problematização da vida social. Por um lado, ele é uma arena onde há debates e diálogos; por outro, é um lugar das inscrições e do reconhecimento do interesse público sobre determinadas dinâmicas e transformações da vida social. Todas as cidades dispõem de lugares públicos que correspondem à imagem da cidade e de sua sociabilidade (GOMES, 2002).

De fato, espaço público não se refere apenas a um arranjo físico espacial de apropriação coletiva, com características próprias decorrentes de sua situação jurídica, urbanística e técnica, é também um espaço social que possibilita determinadas práticas sociais, econômicas e políticas, em que ocorrem processos mais abrangentes em virtude de particularidades e singularidades existentes na sociedade. A rua como um dos principais espaços públicos, não é simplesmente um lugar de passagem e circulação, é também o lugar do encontro, do movimento, da mistura como teatro espontâneo.

Para Leite (2004), a política dos usos cotidianos e públicos, que demarcam diferenças e criam transgressões na paisagem urbana ao subverter usos esperados, constitui lugares que configuram e qualificam os espaços urbanos como públicos, na medida em que os tornam locais de disputas práticas e simbólicas sobre o direito de estar na cidade, de ocupar seus espaços, de traçar itinerários, de pertencer, enfim, de ter identidade e lugar. Nesse caso, para o autor uma noção de espaço público requer, para qualificar como público, determinados espaços urbanos da vida contemporânea. Através do reconhecimento de que certas manifestações públicas não se estruturam em qualquer rua, mas apenas em certos espaços, os quais têm sentidos para os atores envolvidos. É neste contexto de situações e relações que os diferentes usos do solo urbano se intensificam, marcando o desenvolvimento da cidade. Assim, pois, não é mais possível "olhar" o Centro de Fortaleza sem "enxergar" o trabalhador de rua nos espaços públicos.

A partir dos anos 1980, o Centro de Fortaleza perdeu sua histórica visibilidade, principalmente com a transferência de órgãos públicos, como o Palácio do Governo do Estado, Palácio do Bispo, Câmara Municipal e Assembleia Legislativa, reduzindo sua centralidade em relação às outras zonas da cidade, como a orla marítima, os bairros de Meireles e Aldeota. O surgimento dos shopping centers fortaleceu o comércio especializado (bancos, clínicas, escolas) voltado para uma clientela mais específica que busca segurança, limpeza, conforto, facilidade de acesso e de trânsito. 
Neste processo, no Centro permaneceram, principalmente, as atividades tradicionais ligadas ao comércio varejista, sendo encontrada grande quantidade de mercadorias, tais como tecidos, aviamento, material elétrico, plástico, descartável etc. Os gêneros de indústrias de transformação predominantes são confecções/calçados e gráficas que se enquadram no perfil de empresas de pequeno porte. É comum o argumento divulgado pela mídia de que as ocorrências de "marginais, prostituição, moradores de rua, atividades informais, catadores de papel, sujeira, buracos, insegurança, barulho, congestionamentos" contribuem para a situação de declínio em que se encontra o lugar. Difunde-se cada vez mais a concepção de que determinados espaços públicos são "lugares pobres para os pobres", e o que é público se identifica como algo que não tem qualidade e deve ser utilizado pela população carente (hospitais, escola, parques, praças).

No espaço público da cidade contemporânea, os modos de consumo são os elementos determinantes, diferença e desigualdade articulam-se no processo de apropriação espacial, definindo uma acessibilidade que tem uma dimensão de classe evidente, que atua na territorialização desses espaços. Para Gomes (2002), a situação dos espaços públicos na atualidade apresenta dois resultados. No primeiro, o uso dos espaços públicos se reduz, a área de sociabilidade tem uma pequena extensão, onde a convivência passa a ser apenas com os semelhantes. Esta situação corrobora para esclarecer por que os shoppings centers estão constantemente lotados. O segundo resultado desse processo é que, ao abdicar dos espaços comuns e renunciar em partilhar um território coletivo de vida social, nasce o fenômeno da ocupação dos espaços públicos apenas pelos pobres.

$\mathrm{Na}$ lógica de apropriação dos espaços públicos pelos trabalhadores de rua, geralmente os pontos de trabalho são definidos pela presença de inúmeras repartições públicas e equipamentos particulares, até porque a permanência no espaço público geralmente está relacionada ao horário de funcionamento da atividade no espaço privado.

A condição necessária para a constituição da venda na rua diz respeito a "aparente" facilidade de acesso e os trabalhadores tornam-se sujeitos na construção de práticas socioeconômicas e buscam a partir da apropriação garantir o exercício "legítimo" de suas atividades econômicas. Este trabalho tem repercussões significativas para a viabilização da reprodução social desses trabalhadores, sendo os locais de trabalho para os cadastrados fixos, o que assegura o exercício de suas atividades.

Segundo dados da Prefeitura Municipal de Fortaleza (PMF) e da Aprovace (2005), no Centro de Fortaleza existem 970 trabalhadores cadastrados no DCA. De acordo com a pesquisa da Aprovace, $67 \%$ dos trabalhadores possuem o termo de permissão expedido pela Prefeitura, enquanto $29 \%$ não o possuem e $4 \%$ não opinaram. A situação de cadastrados denota uma segurança e proteção legal da PMF, pois a Lei $9.300^{4}$ (PREFEITURA MUNICIPAL DE FORTALEZA, 2004) assegura os direitos e deveres dos cadastrados.

Sou cadastrado, você trabalha sossegado, fica com o psicológico, emocionalmente bom, porque o pessoal que não é cadastrado aqui tem uma dificuldade muito grande pra trabalhar [...]. Consegui o ponto há três anos, com muito esforço, trabalhando, e o 'rapa' me perseguindo. Eu juntei um dinheiro, e o rapaz aqui quis vender este cadastro, aí eu peguei, tinha uma economia e comprei (Entrevistado A, 33 anos, 13 anos trabalhando na rua).

O Centro de Fortaleza apresenta limitação para comportar todos os trabalhadores. A reduzida capacidade de abrigá-los no espaço público determinada pela PMF resulta, sistematicamente, em uma grande massa de não-cadastrados que pode chegar a 4.500 trabalhadores. De acordo com os entrevistados, os espaços públicos do Centro não comportam mais tantos trabalhadores. Como mostra este relato:

\begin{abstract}
A rua já esta cheia, acho que não pode encher, já tem muita gente. Tem que entender que cada caso é um caso. Existem aquelas pessoas que necessitam mesmo, não tem outro meio (Entrevistado D, 52 anos, 15 anos trabalhando na rua).
\end{abstract}

Historicamente, a relação dos trabalhadores de rua do Centro, principalmente os não-cadastrados, com as diferentes gestões municipais foi caracterizada por tolerância por meio de alianças entre trabalhadores com o poder público, como também pela repressão e por ações violentas realizadas pelo "rapa". Em Fortaleza, aos trabalhadores de rua nãocadastrados, restavam como estratégias de apropriação dos espaços públicos: deslocarem-se para mercados e feiras livres na periferia; continuarem na área apropriada mesmo com o perigo de ter sua mercadoria apreendida pela fiscalização; permanecerem nas colunas das portas e entrada das lojas, na maioria das vezes, com o pagamento de uma taxa ao dono e/ou responsável pelo estabelecimento ou a ocupação de áreas onde não existia a fiscalização ostensiva do DCA e que dispunha de um fluxo considerável de transeuntes.

Essas formas de apropriação necessitam de uma capacidade de deslocamento e de mobilidade. É o caso visível das esquinas, onde a ocupação é sempre presente. Um entrevistado não-cadastrado e que está nessa atividade há 20 anos, nas principais ruas do centro relata: 
Quando eu estou aqui, quando eles vêm, eu saio, vou pro outro lado. E assim vai. [...] Fico só andando, caso o 'rapa' venha pode tomar tudo (Entrevistado B, 33 anos, 20 anos trabalhando na rua).

Convém frisar que os trabalhadores de rua nãocadastrados formam um grupo vulnerável submetido à violência, às perseguições e às repressões, principalmente por não fazer parte do sistema de proteção material, estando, portanto fora da ordem de direitos, dependendo de uma política de "vistas grossas" por parte das autoridades. Essa mescla de fatores revela como os trabalhadores e os poderes públicos operam dentro de certa "invisibilidade social". Então, a sua lógica, seria uma "ilegalidade consentida", normatividade extralegal, autoregulação, estratégia de sobrevivência, afirmação do direito ao trabalho (MALAGUTI, 2000). É importante destacar ainda que o comércio de rua é um continuum do formal, havendo uma clivagem entre ambos que é econômica, social, política e não tãosomente legal, pois a chamada "ilegalidade" é uma consequência e não uma causa.

A desorganização do Estado, a sua incapacidade de fiscalizar e controlar, aliada aos altos custos da economia em termos de impostos e encargos trabalhistas, leva o acelerado crescimento da economia informal a todos os níveis da sociedade urbana. Esta tese já foi analisada no trabalho de Soto (1986 apud LOPES, 1996) do ponto de vista econômico. Nessas atividades, as pessoas envolvidas e a sociedade em geral ficam mais à vontade se a lei nominalmente aplicável não for cumprida. Poderíamos dizer que a informalidade acontece quando o "direito impõe regras, que excedem o limite nominativo socialmente aceito, não ampara as expectativas, escolhas e preferências de quem não pode cumprir as regras e o Estado não tem a capacidade coercitiva suficiente" (SOTO, 1986 apud LOPES, 1996, p. 29).

Para Itikawa (2006), o histórico da inoperância das leis revela o quanto elas podem se descolar da realidade e se transformar em uma peça ideológica mediante uma visão tecno-burocrática que desconsidera os conflitos. Itikawa (2006) resume esta precariedade institucional no tripé: repressão e criminalização versus clandestinidade estrutural consentida versus arbitrariedade e abuso.

O aparelho da repressão do poder público mostra o quanto a criminalização do trabalho nas ruas é autoritária e arbitrária. A apreensão das mercadorias sistematicamente é uma das faces da truculência usada nesses casos, justificada por medidas de higiene, segurança e de revitalização dos espaços públicos.

Segundo Frúgoli Jr. (1995; 2004), a presença dos trabalhadores nos espaços públicos da cidade é assegurada por regras e códigos informais conhecidos por seus integrantes, com o estabelecimento de uma combinação de princípios de solidariedade, de hierarquia. A existência de lideranças que atuam como mediadores dos interesses do grupo com a sociedade e suas práticas dependem de um tipo de apropriação privada do espaço público, com a formação de pontos onde muitas vezes predomina a lógica do poder e da violência.

O comércio de rua é construído sob a ótica do trabalho precarizado, com regras, códigos, intercâmbio entre iguais, que são conhecidos tão-somente por seus integrantes, e o estabelecimento de princípios de solidariedade, de hierarquia, com a legitimidade de líderes (diretores da APROACE) que devem buscar mediar os interesses dos trabalhadores com os diversos segmentos da sociedade civil e do poder público. Uma tensão percebida se estabelece entre os trabalhadores, independentemente de serem cadastrados ou não: é a concorrência, pois estão sujeitos às leis do mercado (preço baixo, mercadoria de qualidade $)^{5}$, que regula seu comércio e pode significar melhores vendas, e, em consequência, maiores condições de assegurar a sua sobrevivência.

A Organização Internacional do Trabalho (OIT) realizou uma pesquisa na América Latina sobre o comércio de rua destacando os prós e os contras do comércio ambulante. Nos argumentos contra, são destacados: uso pouco estético das zonas de pedestres, cerceamento da liberdade de circulação, problemas higiênicos de contaminação de produtos e ausência de sanitários para os ambulantes, redução do espaço físico das ruas que facilita a pequena delinquência com passantes, prejuízo parcial ao comércio estabelecido, perda de tributos pela administração e pelo fisco. Já na defesa do comércio ambulante são enumerados os seguintes aspectos: melhores preços ao consumidor, inserção de pessoas com dificuldade de inclusão normal no mercado de trabalho, sustento para a maioria das famílias, redução do desemprego e da delinquência (YÁZIGI, 2000).

\section{A apropriação dos espaços públicos do Centro de Fortaleza pelos trabalhadores de rua}

Partimos do pressuposto que os trabalhadores de rua ao se apropriarem dos espaços públicos do Centro de Fortaleza fazem um contra-uso (LEITE, 2004) que subverte os usos esperados, sobretudo a partir das tensões que se erguem das diferentes possibilidades de uso e dos sentidos atribuídos pelos moradores e frequentadores. Essa reflexão está fundamentalmente ligada à necessidade de desenvolver a noção de espaço público em um sentido muito específico, pois dela poderemos partir para uma análise mais profunda a respeito da maneira como os trabalhadores legitimam sua situação de apropriadores desses espaços 
na cidade que revele o trabalho enquanto central para pensarmos não apenas nessa apropriação, mas na desigualdade que marca a vida dessas pessoas. Diante disso, a discussão sobre o espaço público ganha centralidade. Para os 20 trabalhadores entrevistados o espaço público é, antes de qualquer coisa, a praça, a rua, a praia, um tipo de espaço, onde não haja obstáculos à possibilidade de acesso e participação de qualquer tipo de pessoa "fazer o que gosta".

É um lugar em que as pessoas possam fazer o que gostam, andar, comprar, vender. Ele é público, todo mundo pode passear e fazer o que gosta (Entrevistado C, 29 anos, dois anos trabalhando na rua).

Os trabalhadores entrevistados argumentam que a utilização dos espaços públicos como única saída para a sua sobrevivência é defendida mesmo contrariando as leis estabelecidas. Desse modo, sobreviver na rua é constituir uma nova forma de uso do espaço público, e também uma maneira de subverter os padrões formais do mercado na sociedade capitalista alicerçada no trabalho assalariado.

Eu acho que se a gente está transgredindo alguma coisa da lei, isso hoje no Brasil é o mínimo. É o mínimo porque o que a gente quer é simplesmente alimentar nossa família [...]. (Entrevistado I, 29 anos, dois anos trabalhando na rua). balhadora, considerada em seu conjunto, gasta todo o seu salário apenas para sobreviver. Para se sustentar tem de consumir uma quantidade determinada de meios de subsistência, precisa de outra quantidade para criar os filhos que a possa substituir no mercado de trabalho. Desta forma, o primeiro pressuposto de toda existência humana "é que os homens devem estar em condições de viver para poder fazer história. Mas para viver, é preciso antes de tudo comer, beber, ter habitação, vestir-se e algumas coisas mais" (MARX, 1987, p. 39).

Na lógica de apropriação dos espaços públicos, como contra-uso, o debate sobre o público e o privado ganha centralidade. Essa discussão gerou polêmica entre os trabalhadores que apresentavam dúvidas sobre a questão, principalmente quando perguntado se eles com suas atividades não atrapalham os frequentadores do Centro. Há uma unissonância dos trabalhadores entrevistados, como denotam estes depoimentos:

Os frequentadores acham é bom, porque não precisam entrar na loja (Entrevistado, F, 56 anos, três anos trabalhando na rua).

Não é uma privatização, é um espaço muito pequeno (Entrevistado, Q, 56 anos, três anos, trabalhando na rua).
A apropriação dos espaços públicos como locais de trabalho é justificada pelos trabalhadores, como normal, natural, necessária para a sobrevivência, logo relacionada à importância de ganhar a vida honestamente. Constatamos que os trabalhadores de rua esforçam-se para serem reconhecidos como trabalhadores, para fugir do estigma de "vagabundo", "marreteiro", "marginal", e quase sempre associado ao comerciante de rua.
Todas estas respostas apontam para uma complexa situação em que a princípio transparece uma naturalidade, uma normalidade neste contra-uso. Na apropriação dos espaços públicos se concretizam as diferenças de seu uso através de práticas sociais, econômicas e políticas, se caracterizando como locus de socialização, de interações, de ações comuns e de sociabilidade específica de determinados grupos socioculturais (LEITE, 2004).
Eu me sinto honrado, não estou roubando [...]. Se a metade da marginalidade viesse fazer o que eu faço aqui, ia melhorar bastante a violência (Entrevistado, B, 33 anos, 20 anos trabalhando na rua).

Para os trabalhadores, verificamos uma unanimidade quanto à apropriação com direito ao trabalho. A necessidade de sobreviver justifica a apropriação dos espaços públicos, para garantir acesso aos "mínimos vitais". Marx (1987) já anunciava que a classe tra-

\section{Resistências e lutas para assegurar pela apropriação dos espaços públicos o direito ao trabalho}

Historicamente a resistência dos trabalhadores dava-se principalmente contra a PMF que utilizava a repressão e a violência. Foi criada toda uma estrutura de fiscalização, como a Guarda Municipal, popularmente chamada de "rapa", com poder policial que apreendia as mercadorias e prendia os trabalhado- 
res. Em momentos de confronto, a PMF chegou a empregar todo o aparato repressivo, inclusive a Polícia Militar, para assegurar o disciplinamento e o ordenamento. Apesar de toda a repressão, os trabalhadores utilizavam estratégias para a apropriação dos espaços públicos proibidos, mostrando que somente a repressão não iria garantir o "ordenamento do Centro" (DANTAS, 2005).

A resistência dos trabalhadores ${ }^{6}$ data dos anos 1940, período em que a PMF inicia o processo de normalização do Centro por pressão de diferentes segmentos sociais: a impressa, o legislativo municipal, os comerciantes e a sociedade civil. Na década de 1980, período de crescimento do comércio de rua no Centro, eram constantes as perseguições e violência por parte da fiscalização da prefeitura através da Guarda Municipal (JUCÁ, 2003).

Em 1982, foi criada a Aprovace, que vem mantendo uma relação de parceria com a PMF e, esta, em contrapartida, fortalece a entidade ao condicionar a afiliação como exigência à alocação em espaços permitidos à comercialização de mercadorias. A Aprovace busca estabelecer o diálogo com os trabalhadores e a PMF para discutir estratégias de reordenamento e disciplinamento do Centro, com o intuito de colaborar com o poder público. Uma das propostas defendidas pela Aprovace é a liberação de uma rua do Centro das 18:00 às 22:00 horas, para o comércio desses trabalhadores.

Para os trabalhadores entrevistados, sua atividade é importante para a cidade e, nesse sentido, apresentam algumas reivindicações para a PMF, direcionadas para as suas condições de trabalho, com $\mathrm{o}$ intuito de atender melhor à população.

- Desenvolver ações concretas para desmistificar as ideias de que os trabalhadores sejam "marginais", "malandros", que não devam ser reconhecidos ou, ainda, da existência de uma relação direta entre o ganho adquirido pelo comércio de rua e a perda do comércio formal. Ao contrário, em algumas áreas este comércio tem atraído consumidores em potencial também para os lojistas da região do Centro de Fortaleza.

- Traçar o perfil e mapear os locais mais apropriados pelos trabalhadores, para estabelecer áreas especializadas na comercialização de artesanatos, eletro-eletrônicos, confecções, alimentação etc., como também a organização dos não-cadastrados em um espaço fixo, fiscalizado pela PMF.

- Tomar medidas que possibilitem o aumento dos consumidores e as melhores condições de trabalho, com linha de crédito, cursos sobre técnica de vendas e atendimento ao cliente, banheiros públicos, lixeiras, segurança, estacionamentos. Organização dos pontos de venda com bancas maiores e toldo para proteger contra o sol e a chuva.

Constatamos nas entrevistas que todos ressaltam a importância da organização dos trabalhadores de rua. Entretanto a falta de tempo, de união, de experiência, as incertezas quanto à permanência na atividade, as irregularidades dos rendimentos, a concorrência diária, são fatores que dificultam sua organização para lutar por melhores condições de vida, resultando em uma atitude de espera e de dependência em relação a PMF, por exemplo.

A gente tem que se organizar; em tudo que a gente vai fazer no mundo hoje a gente tem que se organizar. Eu acho que cabe muito aos governantes olharem pra nossa situação e ver o que eles podem fazer pela gente (Entrevistado I, 29 anos, dois anos trabalhando na rua).

Os problemas enfrentados por aqueles que sobrevivem nas ruas de Fortaleza chegam a sujeitar as pessoas a uma situação limite repercutindo no plano das representações. Pois o trabalho vai além do acesso a bens materiais, mas também, garante bens imateriais como a honra, um traço da própria autorepresentação do trabalhador aos olhos dos outros, para não passar a ideia supostamente vergonhosa de ser um fracassado ou inepto. Até porque, às vezes, o desempregado passa por dificuldades econômicas para prover a si e a sua família, como também, sofre a sensação de falha quando a responsabilidade pelo desemprego é depositada sobre os ombros do próprio trabalhador.

Nessa perspectiva, a exploração se intensifica, no caso particular dos trabalhadores de rua, constata-se ausência de qualquer direito relacionado à velhice, à doença, a acidentes, ao desemprego. Esta situação causa incerteza, insegurança e angústia, pois revela uma dicotomia entre a concepção dos trabalhadores sobre o trabalho que estrutura suas vidas socialmente e economicamente, e por outro lado, a inexistência de condições reais para que essa representação se sustente e se concretize em uma sociabilidade capitalista.

A gente está numa inconstante. Se amanhã, Deus defenda, eu cair doente, não terei auxílio nenhum (Entrevistado I, 29, dois anos trabalhando na rua).

Para Ramires (2001, p. 173), a realidade dos trabalhadores de rua se caracteriza como a ruptura do contrato social, os que não estão inseridos no mercado formal são jogados à própria sorte, sem nenhuma reação da sociedade. "Restam apenas indivíduos isolados uns dos outros, que parecem não ter qualquer relação entre si, o que representa sério comprometimento da cidadania." Dessa forma, os trabalhadores de rua 
veem seus direitos negados e estão sujeitos à violência, discriminação, humilhação e ao preconceito.

\begin{abstract}
Não acho um bom exemplo para os meus filhos, fica um mau exemplo. A pessoa só trabalhando na rua, sem estudo, às vezes passa humilhação dos próprios compradores, às vezes as mercadorias quebram, em quinze dias querem voltar, querem chamar a Polícia e dizem que é coisa importada. Tem as coisas boas e as coisas ruins nesse trabalho (Entrevistado, A, 33, 10 anos trabalhando na rua).
\end{abstract}

Em 2006, a ONG Organização Fórum Centro Vivo elaborou o dossiê Violação dos direitos humanos no centro de São Paulo - Proposta para política pública, sobre a violência, no qual foram analisadas diversas formas de negação dos direitos dos trabalhadores de rua, de onde destacamos:

- Negação do direito à igualdade e à não-discriminação (Art. $3^{\circ}$ e $5^{\circ}$ da Constituição Federal). A discriminação dos trabalhadores acontece a partir da repressão sistemática e violenta, bem como por práticas que contribuem para a criminalização e estigmatização desse segmento. Nesse caso, é violado o Art. $5^{\circ}-\S$ III onde diz que ninguém será submetido à tortura nem a tratamento desumano ou degradante.

- Negação do direito à vida e à segurança (Art. $5^{\circ}$ da Constituição Federal), violando princípios fundamentais da dignidade da pessoa humana, cidadania, valores do trabalho e da livre iniciativa.

- Negação do direito ao devido processo legal. De acordo com o Art. $5^{\circ}$ (§ LXXIV da Constituição Federal), o Estado prestará assistência jurídica integral e gratuita aos que comprovarem insuficiência de recursos. Inserem-se aí os trabalhadores de rua a quem devem ser garantidos os direitos à defesa, a um devido processo, bem como à assistência judiciária integral. Negação do direito à propriedade (Art. $5^{\circ}$ da Constituição Federal). O Estado deve garantir a inviolabilidade do direito aos bens materiais de propriedade e posse dos trabalhadores, tais como bancas, instrumentos de trabalho e mercadorias.

- Negação do direito ao trabalho (Art. $6^{\circ}$ e $7^{\circ}$ da Constituição Federal). Impedimento do direito ao exercício de trabalho livre, ofício ou profissão, em função da repressão sistemática aliada à ausência de políticas públicas e alternativas voltadas para os trabalhadores do comércio de rua que visem a oportunidades de renda e sobrevivência. No Art. $5^{\circ}$ (§ XIII da Constituição Federal) é assegurado o livre exercício de qualquer trabalho, ofício ou profissão, aten- didas as qualificações profissionais estabelecidas na lei (BRASIL, 2004).

Essa realidade demonstra que se trata de um segmento que não foi incorporado nas lutas dos sindicatos tradicionais, que tem encontrado muitas dificuldades diante da magnitude do desafio, da defesa do emprego e dos salários, num quadro de transformações estruturais por que passa o mundo do trabalho, com terceirização, precarização, desemprego, redução da massa de trabalhadores formalmente empregados. Entretanto, Antunes (1999, p. 217) destaca que o despossuído é situado "potencialmente como um sujeito social capaz de assumir ações mais ousadas, uma vez que esses segmentos sociais não têm mais nada a perder no universo da sociabilidade do capital."

\section{Considerações finais}

Na lógica de apropriação dos espaços públicos, a cidade aparece como produto apropriado de formas diferentes por seus habitantes, mostrando que é um espaço contraditório, lugar dos conflitos permanentes, renovados, lugar do silêncio e dos gritos: "o conflito não aparece sempre nem é dito. Evita-se falar dele e torná-lo manifesto. Mas ele está aí, constante, latente, implícito" (LEFEBVRE, 1991, p.87).

A relação entre Estado e sociedade torna-se fundamental para revelar as mediações estabelecidas e construídas pelos diversos segmentos sociais, que se organizam reivindicando seus direitos. No que diz respeito à participação da Prefeitura Municipal de Fortaleza, observa-se um conjunto de frentes de intervenção que revelam a sua dinâmica contraditória. Ao mesmo tempo em que assume funções de regulador do comércio de rua, incorporando parte das reivindicações dos trabalhadores, também responde demandas dos lojistas. Os trabalhadores que resistem e lutam para assegurar seu espaço de trabalho, e consequentemente de sobrevivência, enquanto os segmentos dos lojistas reivindicam ações enérgicas da PMF para "resolver", fiscalizar, normatizar esta situação considerada como um "grave problema" que afeta diretamente a economia formal do Centro histórico e de toda a cidade. Apesar de todas as críticas de setores lojistas acerca da concorrência desleal praticada pelo comércio de rua, observa-se certa simbiose que já faz parte da história dos trabalhadores e de alguns lojistas. Os trabalhadores alugam espaços nos fundos das lojas para guardar mercadorias, igualmente pagam aos lojistas para exercerem suas atividades em frente àquelas lojas. Além disso, fazem suas compras em atacadistas e produtores estabelecidos na própria região.

O comércio de rua permite aos pobres ter acesso ao consumo e ratifica a permanência deste tipo de negócio nos espaços públicos de Fortaleza. De for- 
ma concreta, esse comércio também desempenha uma importante função "absorvedora de choques" no mercado de trabalho. Vêm incorporando mão-deobra masculina, adultos em idade produtiva, jovens com baixa escolaridade e sem experiência profissional, como também, trabalhadores mais velhos com baixa escolaridade e com problemas de saúde.

Não resta dúvida que a falta de oportunidade no mercado formal de trabalho é agravada pela baixa escolaridade e pela reestruturação econômica que resulta na diminuição e na eliminação de postos de trabalho. A nova organização do capital permite uma maior produção com a exploração de um menor número de trabalhadores, realidade que produz uma contradição, pois parte da sociedade tem apenas a venda de sua força de trabalho como forma de garantir sua sobrevivência. Sob a égide da lógica do capital, o desemprego crônico é escamoteado, naturalizado, como se não houvesse outra "alternativa", senão conviver com ele. A responsabilidade social pelo desemprego é atribuída ao trabalhador que deve buscar suas próprias "soluções", muitas vezes a "saída" possível é a apropriação dos espaços públicos da cidade.

Portanto, sobreviver na rua subverte as leis e os padrões formais do mercado na sociedade capitalista alicerçada no trabalho assalariado, esta apropriação dos espaços públicos pelos trabalhadores de rua altera usos esperados com um contra-uso que é estabelecido por disputas/tensões/resistências pelo direito ao trabalho.

\section{Referências}

ANTUNES, R. Os sentidos do trabalho - Ensaio sobre a afirmação e a negação do trabalho. São Paulo: Boitempo, 1999.

APROVACE - Associação Profissional do Comércio de Vendedores Ambulantes e Trabalhadores Autônomos do Ceará. Relatório analítico acerca das pesquisas aplicadas junto aos ambulantes do centro de Fortaleza, do Centro de Pequenos Negócios dos Vendedores Ambulantes (CPNVA) e de sua Associação de suporte. Fortaleza, dez. 2005. (Digitado).

BRASIL. Constituição da República Federativa do Brasil. São Paulo: Atlas, 2004.

DANTAS, E. W. C. Apropriação do espaço público pelo comércio ambulante: Fortaleza-Ceará-Brasil em evidência (1975 a 1995). Disponível em: <http://www.ub.es/geocrit/ sn/sn-202.htm>. Acesso em: 24 abr. 2005.

DOSSIÊ DE DENÚNCIA. Violação dos direitos humanos no centro de São Paulo - Proposta para política pública. Organização Fórum Centro Vivo, São Paulo, 2006. (Digitado).
FRÚGOLI JÚNOR, H. Espaços públicos e interação social. São Paulo: Marco Zero, 1995.

. A questão dos camelôs no contexto da revitalização do centro da metrópole de São Paulo. In: SOUZA, M. A. A. de et al. Metrópole e globalização - conhecendo a cidade de São Paulo. São Paulo: Editora CEDESP, 2004.

GOMES, P. C. da C. A condição urbana. Ensaios de Geopolítica da Cidade. Rio de Janeiro: Bertrand Brasil, 2002.

ITIKAWA, L. Geometrias da clandestinidade: o trabalho informal no centro de São Paulo. Disponível em: $<$ http:// www.centrodametropole.org.br/>. Acesso em: 23 jul. 2006.

JUCÁ, G. N. M. Verso e reverso do perfil urbano de Fortaleza (1945-1960). São Paulo: Annablume, 2003.

LEFEBVRE, H. A vida cotidiana no mundo moderno. São Paulo: Ática, 1991.

LEITE, R. P. Contra-uso da cidade: lugares e espaço público na experiência urbana contemporânea. Campinas: Editora da Unicamp, 2004.

LOPES, R. A economia informal no Rio de Janeiro: problema ou solução. Rio de Janeiro: Mauad, 1996.

MALAGUTI, M. L. Crítica à razão informal - A imaterialidade do salariado. São Paulo: Boitempo, 2000.

MARX, K. Introdução à crítica da economia política. In: Os Pensadores. São Paulo: Abril Cultural, 1987. p. 103-125.

; ENGELS. F. A Ideologia Alemã. Tradução de José Carlos Bruni e Marco Aurélio Nogueira. São Paulo: Hucitec, 1987.

PREFEITURA MUNICIPAL DE FORTALEZA. Secretaria Municipal de Desenvolvimento Urbano e Infra-Estrutura (Seinf). Disponível em: <http://www.seinf.fortaleza.ce. gov.br/>. Acesso em: 21 fev. 2007.

.Decreto lei N. 9300 de 17.01.1994 - Regulamenta a atividade de comércio ambulante do Município de Fortaleza. Fortaleza, 1994. (Mimeografado, cópia dos arquivos da PMF, disponibilizados para pesquisa).

RAMIRES, F. J. Severino na metrópole - A negação do trabalho na cidade de São Paulo. 218 p. Dissertação (Mestrado em Sociologia) - Faculdade de Filosofia, Letras e Ciências Humanas da Universidade de São Paulo, 2001.

YAZIGI, E. O mundo das calçadas - Por uma política democrática de espaços públicos. São Paulo: Humanitas -FFLCH/USP, 2000. 


\section{Notas}

1 Este artigo é um recorte da tese de doutorado em Serviço Social defendida na Universidade Federal de Pernambuco em 2007, com o título: A lógica da apropriação dos espaços públicos na cidade de Fortaleza pelo trabalhador de rua. Diante da heterogeneidade do termo, nesta pesquisa camelôs, ambulantes, vendedores e comerciantes são identificados como trabalhadores de rua no intuito de englobar todas as especificidades desta realidade que se caracteriza por um intenso processo de precarização e por se materializar nos espaços públicos da cidade. A categoria "trabalhador de rua” também é utilizada por Frúgoli Jr. (1995) e no Dossiê Denúncia: Violação dos direitos humanos no Centro de São Paulo(2006).

2 A cidade de Fortaleza entrou no século 21 comíndices sociais críticos, ou seja, as desigualdades sociais são elevadas até para o modelo brasileiro. A cidade apresentou em 2003 um crescimento desordenado, coma escassezde 144 milmoradias, a existência de 600 favelas e com 92 áreas de riscos. Nesse cenário, também é preocupante a situação do mercado de trabalho, que espelha a fragilidade da economia, pela considerável pressão por criação de empregos e pela relevância do setor informal. Esse contexto insere-se no modelo fortemente concentrado de renda. Em 2006, menos de $1 \%$ da população apropria-se de $13 \%$ da renda global, enquanto outros $33 \%$ detêm apenas $8 \%$ (PREFEITURA MUNICIPALDEFORTALEZA, 2007).

3 O perfil dos trabalhadores de rua revela que $72 \%$ da mão-deobra são masculinos e $28 \%$, femininos. Os trabalhadores têm na sua composição etária, entre 21 e 40 anos, somando $45 \%$ do total. O segundo grupo, formado por pessoas de 41 a 60 anos, totaliza $35 \%$. E ainda $15 \%$ entre 17 a 20 e $5 \%$ com 61 anos. Estes dados demonstram um perfil de adultos no auge da vida produtiva. Em contrapartida, a faixa de 21 a 40 anos seria a de maior probabilidade de conseguir se inserir no mercado formal, e, no entanto, representam maior porcentagem, $45 \%$ dentro desta atividade em questão. Dos entrevistados, $82 \%$, trabalham por conta própria e são donos dos pontos e das mercadorias comercializadas e 11\% são permissionários (trabalhadores cadastrados na Prefeitura Municipal de Fortaleza e que sublocam seus pontos). Em relação ao tempo de serviço, $42 \%$ dos trabalhadores estão há cinco anos nessa atividade, enquanto $22 \%$ entre seis e 10 anos, $21 \%$ entre 11 a 20 anos e $14 \%$ há mais de 20 anos (APROVACE, 2005).

4 ALei No 9.300 de 17 de janeiro de 1994, no Título III do Preço Público. Art.16: “O preço público a ser pago pelos permissionários, em cumprimento das disposições contidas neste título, será calculado levando em conta o tipo de equipamento a ser utilizado e sua localização.”No Título IV: "Dos equipamentos de trabalho serão padronizados pelo DCA com especificações adequadas aos tipos de comércio ou serviços conforme discriminação a seguir: Bancas de jornal e revistas - bancas estacionárias - tabuleiros estacionários - boxe de pré-moldados ou concretos - cabina de fibra caixote-carrinho-carro-reboque-carrocinha-tabuleiro."

5 No comércio de rua do Centro de Fortaleza, as mercadorias comercializadas apresentam grande diversidade (de acordo com a época do ano, há a predominância de determinadas mercadorias), ocorre a concentração em torno dos negócios de: alimentação, confecção, acessórios, miudezas, bombom/ cigarro, óculos/relógio, CD/DVD. Os trabalhadores de rua participam da economia urbana colaborando para o processo de reprodução do capital, arcando com os custos relativos à sua reprodução como força de trabalho e sem maiores dispêndios para o capital(MALAGUTI, 2000).

6 Éemblemático registrar que em 1994 ocorreu a realização de missa organizada pelos trabalhadores do Centro, comunidades eclesiais de base, partidos políticos de esquerda e algumas entidades de classes na Praça José de Alencar, em protesto à violência sofrida pelos trabalhadores a partir das ações violentas de fiscais e da Polícia Militar (JUCÁ, 2003).

\section{Aurineida Maria Cunha}

Doutora em Serviço Social pela Universidade Federal de Pernambuco (UFPE)

Professora da Universidade Estadual do CearáUECE

\section{UECE}

Av. Parajana 1700

Campus do Itaperi

Fortaleza - Ceará

CEP: 60822-460 